\title{
COMPETÊNCIA LEGISLATIVA DO MUNICÍPIO EM MATÉRIA AMBIENTAL: O CASO DAS SACOLAS PLÁSTICAS
}

\section{COMPETENCIA LEGISLATIVA DEL MUNICIPIO EN MATERIA AMBIENTAL: EL CASO DE LAS BOLSAS PLÁSTICAS}

\author{
${ }^{1}$ Wilson Antônio Steinmetz \\ ${ }^{2}$ Susanna Schwantes
}

\section{RESUMO}

Este artigo tem por objeto o problema da definição e dos limites das competências legislativas do Município em matéria ambiental. O marco normativo é a Constituição Federal de 1988. A referência empírica problematizante são leis municipais que disciplinam o uso de sacolas plásticas, com a finalidade e justificativa de proteger o meio ambiente, e decisões judiciais sobre a constitucionalidade dessas leis. Argumenta-se que, embora não exista previsão expressa no texto constitucional brasileiro, o princípio da subsidiariedade pode ser validamente deduzido do modelo federativo delineado na Constituição, tornando-se um postulado decisivo para orientar a atuação legislativa do Município em matéria ambiental. Adota-se uma metodologia analítica e sistemática, compreendendo os aspectos conceituais, normativos e empíricos do problema.

Palavras-chave: Meio ambiente, Município, Competência legislativa, Princípio da subsidiariedade

\section{RESUMEN}

Este artículo se centra en el problema de la definición y los límites de las competencias legislativas del municipio en materia de ambiente. El marco regulatorio es la Constitución Federal de 1988. La referencia empírica son las leyes locales que rigen el uso de bolsas de plástico, con la finalidad y justificación de la protección del medio ambiente, y las decisiones judiciales acerca de la constitucionalidad de las leyes. Se argumenta que, si bien no existe una disposición expresa en la Constitución brasileña, el principio de subsidiariedad puede ser deducido del modelo federativo esbozado en la Constitución, por lo que es un principio clave para orientar la función legislativa del Municipio en el ámbito ambiental. Adopta una metodología analítica y sistemática, que comprende los aspectos conceptuales, normativos y empíricos del problema.

Palabras-claves: Ambiente, Municipio, Competencia legislativa, Principio de la subsidiariedad

1 Doutor em Direito pela Universidade Federal do Paraná. Profssor pela Universidade de Caxias do Sul. Universidade de Caxias do Sul - UCS, Rio Grande do Sul. Brasil - E-mail: wilson.steinmetz@gmail.com 2 Mestranda pela Universidade de Caxias do Sul. Professora pelo Centro Universitário Ritter dos Reis. Centro Universitário Ritter dos Reis - UniRITTER, Porto Alegre - RS. Brasil - E-mail: professorasusanna@ yahoo.com.br 


\section{INTRODUÇÃO}

Este artigo tem por tema as competências constitucionais do Município no âmbito da defesa e proteção do meio ambiente. A Constituição Federal de 1988 elevou o meio ambiente ecologicamente equilibrado à condição de direito fundamental (direito subjetivo) e de bem coletivo pertencente a todo povo. $O$ texto constitucional não se limitou a enunciar mandamentos de natureza principiológica sobre o meio ambiente, mas indicou expressa e detalhadamente deveres e competências de ação (políticas públicas) ao Poder Público, entendido como a totalidade dos entes federativos (União, Estados, Distrito Federal e Municípios).

Não obstante o detalhamento normativo, a Constituição não definiu, de forma clara e precisa, as responsabilidades e competências dos Municípios em matéria ambiental, especialmente as competências legislativas. No art. 24, a Constituição instituiu competências legislativas concorrentes sobre o meio ambiente, citando União, Estados e Distrito Federal. Não há referência ao Município.

Adotando-se a interpretação sistemática, diz-se que, com base no art. 30, I e II, é possível concluir que o Município também pode legislar sobre matéria ambiental, desde que para atender interesse local ou suplementar as legislações federal e estadual. É uma interpretação correta. Contudo, não é suficiente para eliminar, de plano, controvérsias, como é o caso da discussão sobre a constitucionalidade de leis municipais que disciplinam o uso de sacolas plásticas alegando como finalidade e justificativa a proteção do meio ambiente.

Neste trabalho, tem-se por objetivo analisar o problema da definição e dos limites das competências legislativas do Município em matéria ambiental. O tema é problematizado tomando como referência empírica exemplar leis municipais sobre o uso de sacolas plásticas. Com uma abordagem (metodologia) analítica e sistemática, toma-se em consideração as dimensões conceitual, normativa e jurisprudencial do problema investigado.

\section{REPARTIÇÃO DE COMPETÊNCIAS NA ORDEM CONSTITUCIONAL BRASILEIRA}

O Brasil é uma República Federativa, que compreende a União, os Estados, o Distrito Federal e os Municípios, todos autônomos ${ }^{1}$, nos termos da Constituição de 1988, conforme o

\footnotetext{
${ }^{1}$ Autonomia significa capacidade de autodeterminação dentro de um círculo de competências traçadas pelo poder soberano.
} 
art. $1^{\circ}$, combinado com o art. 18, possuindo segundo José Afonso da Silva ${ }^{2}$ dois elementos básicos: existência de órgãos governamentais próprios e posse de competências exclusivas.

Nos dizeres de Paulo Affonso Leme Machado, ${ }^{3}$ o fundamento de toda ordem federal "comunitária" se assenta na sobrevivência dos entes que a compõem, decorrendo uma dupla obrigação: o interesse das partes integrantes e fazer aquilo que é indispensável, para que cada uma possa cumprir o seu papel.

O relacionamento entre Estados, Distrito Federal e Municípios, que forma a União/Brasil, gera um relacionamento de fidelidade, entre todos os entes da federação.

Assim Paulo Affonso Leme Machado ${ }^{4}$ afirma que cabe a União o dever de fazer existir e subsistir a felicidade, que é gerado por vários fatores, mas principalmente a implantação do direito de todos a um meio ambiente ecologicamente equilibrado e propício a uma sadia qualidade de vida (art. 225, caput, da CF)

O sistema de repartição de competências é bastante complexo, buscou a Constituição de 1988 efetuar um equilíbrio federativo, que é constituído pela chamada técnica da enumeração para os poderes da União, segundo o art. 21 e 22 da CF, poderes remanescentes para os Estados, segundo o art. $25 \S 1^{\circ}$ da CF e poderes definidos indicativamente para os Municípios, segundo o art. 29 e 30 da CF. Possuindo ainda áreas comuns, onde há atuação paralela da União, Estados, Distrito Federal e Municípios, nos termos do art. 23 da CF, bem como setores de competências concorrentes, para estabelecer políticas, diretrizes e normas gerais, cabendo à União, enquanto aos Estados e Distrito Federal e aos Municípios somente a competência suplementar, tudo conforme previsto nos arts. 24 e $30 \mathrm{da} \mathrm{CF}$.

Segundo Gilmar Ferreira Mendes ${ }^{5}$ cabe aos Estados algumas competências expressas, segundo o estabelecido no art. $25 \S 2^{\circ}$ e $3^{\circ}$ da $\mathrm{CF}$, quais sejam: exploração de gás canalizado e a instituição de regiões metropolitanas.

\footnotetext{
2 Ibidem, p. 71.

${ }^{3}$ MACHADO, Paulo Affonso Leme. Direito Ambiental Brasileiro. 22. ed. São Paulo: Malheiros, 2014, p. 39.

${ }^{4}$ Ibidem, p. 439.

${ }^{5}$ MENDES, Gilmar Ferreira; COELHO, Inocêncio Mártires; BRANCO, Paulo Gustavo Gonet. Curso de Direito Constitucional. 2. ed. São Paulo: Saraiva, 2008, p. 819.
} 
No modelo federado brasileiro foram criados dois tipos de competências, quais sejam legislativas ou formale administrativas ou materiais. Na competência administrativa ou material a União detêm competência exclusiva (art. 21 da CF), os Estados e Municípios a competência remanescente (art. $25 \S 1^{\circ}$ e art. 30, III a VIII da CF) e competência comum de todos os entes (art. 23 da CF). Já na competência legislativa ou formal a União detêm competência privativa (art. 22 da CF) os Estados (art. $25 \S 1^{\circ}$ e $2^{\circ}$ ) e os Municípios (art. 30, I), bem como competências concorrentes, concedido somente à União, aos Estados e ao Distrito Federal, sendo que a União é responsável pelas regras gerais (art. 24 da CF) e os Estados, Distrito Federal e Municípios a norma suplementar (art. 30, II).

Nas competências legislativas ou formais da União, cabe a edição de leis nacionais, alcançando todos os habitantes do território nacional e outras esferas da Federação e leis federais que incidem sobre os jurisdicionados da União, como os servidores federais e o aparelho administrativo da União. ${ }^{6}$

No que tange a competências comuns, objetivou-se o esforço de todos os entes federados, sendo que dentre eles encontramos: "zelar pela guarda da Constituição, das leis e das instituições democráticas e conservar o patrimônio público, o de proteger o meio ambiente e combater a poluição, melhorar as condições habitacionais e de saneamento básico, proteger obras de arte, sítios arqueológicos, paisagens naturais notáveis e monumentos", prevendo no parágrafo único do art. 23, a edição de Lei Complementar federal que disciplinará a cooperação entre os entes para a realização desses objetivos comuns. (grifos nossos)

Assim, conforme Gilmar Ferreira Mendes, ${ }^{7}$ a finalidade desta Lei Complementar federal é evitar choques e dispersão de recursos e esforços, coordenando-se as ações de pessoas políticas, com vistas à obtenção de resultados satisfatórios, sendo que poderá haver conflito entre estes entes, no momento da execução. Portanto, se o critério de cooperação não funcionar, deverá prevalecer o critério da preponderância do interesse, sendo que o mais amplo da União deve preferir aos mais restritos, dos Estados, ficando o Município hierarquicamente abaixo da União.

\footnotetext{
${ }^{6}$ Ibidem, p. 802 .

${ }^{7}$ Ibidem, p. 820.
} 
Para tanto, foi editada em novembro de 2011 a Lei Complementar $\mathrm{n}^{\circ}$ 140/11, que fixou normas para

a cooperação entre a União, os Estados, o Distrito Federal e os Municípios nas ações administrativas decorrentes do exercício da competência comum relativas à proteção das paisagens naturais notáveis, à proteção do meio ambiente, ao combate à poluição em qualquer de suas formas e à preservação das florestas, da fauna e da flora.

Esta Lei Complementar regulamentou as ações em prol do meio ambiente para todos os entes da Federação, possibilitando a criação de convênios, acordo de cooperação técnica, delegação de atribuições entre outras possibilidades.

$\mathrm{Na}$ competência legislativa ou formal concorrente entre União, Estados e Distrito Federal, segundo o art. 24 da CF, onde encontramos o direito tributário e financeiro, previdenciário e urbanístico, conservação da natureza e proteção do meio ambiente, educação, proteção e integração social da pessoa portadora de deficiência, proteção à infância e à juventude, do patrimônio histórico, artístico, turístico e paisagístico, assistência jurídica, defensoria pública, ministério público etc. (grifos nossos)

Segundo entendimento de Gilmar Ferreira Mendes, ${ }^{8}$ a divisão de tarefas em relação à competência concorrente determina que à União cabe editar normas gerais, não sendo normas exaustivas, e os Estados e o Distrito Federal podem exercer, em relação às normas gerais, competência suplementar (art. 24, § $2^{\circ}$ ), o que também foi concedido ao Município, desde que isso seja necessário ao interesse local. A competência municipal suplementar deverá respeitar as normas federais e estaduais existentes.

Superada a análise da distribuição de competências administrativas e legislativas pelo Poder Constituinte Originário, passamos a verificar a questão da matéria ambiental no sistema de competência constitucional atribuído aos Municípios.

${ }^{8}$ Ibidem

3 INTERESSE LOCAL E SISTEMA DE COMPETÊNCIAS EM MATÉRIA AMBIENTAL 
Os problemas ambientais ultrapassam as fronteiras e sequer respeitam convenções políticas estabelecidas em relação ao meio ambiente. Existem inúmeros problemas de ordem global, nacional, regional, como por exemplo o efeito estufa, mudanças climáticas, destruição da camada de ozônio, extinção de várias espécies, desmatamentos, degradação da água.

A Constituição Federal de 1988 ampliou bastante as competências dos Estados e Municípios, porém, segundo Paulo de Bessa Antunes, ${ }^{9}$ as competências legislativas ambientais, tal como postas na Constituição de 1988, são extremamente confusas e centralizadoras.

A característica de ser centralizada se dá em face de ainda existir monopólio da União para vários assuntos, dentre eles a água, a energia e os recursos minerais.

Dos mais complexos têm sido o tratamento e a definição das competências municipais prescritas no art. 30. Com um elenco de nove incisos, é neste artigo que estão condensados as competências constitucionais municipais, sendo que nos três primeiros incisos estão dispostas as competências legislativas ou formais e nos demais incisos encontramos as competências materiais ou administrativas.

A expressão 'interesse local' utilizada pela Constituição de 1988 no art. 30, I segundo Paulo Affonso Leme Machado, ${ }^{10}$ pode ser utilizada para todo o território do Município, ou somente uma localidade, ou várias localidades que compõem o Município, podendo o próprio interesse local entrar em conflito com o desenvolvimento econômico e a conservação do meio ambiente.

O Município está inserido dentro de um todo maior, devendo cumprir as diretrizes internacionais, constitucionais e legais da federação brasileira.

\footnotetext{
9 ANTUNES, Paulo de Bessa. Federalismo e Competência Ambientais no Brasil. Rio de Janeiro: Lumen Juris, 2007.

10 MACHADO, Paulo Affonso Leme. Direito Ambiental Brasileiro. 22. ed. São Paulo: Malheiros, 2014, p. 442.
} 
Como federação resta perguntar quais são as competências que possuem os Municípios acerca do meio ambiente. Sabe-se que o Município é autônomo, mas organiza-se e se relaciona com a União e os Estados com a finalidade de interesses públicos.

José Joaquim Gomes Canotilho explicita a necessidade integrada dos entes quando se fala em direito ambiental.

Um Estado constitucional ecológico pressupõe uma concepção integrada ou integrativa do ambiente, e, consequentemente, um direito integrado e integrativo do ambiente. Embora não seja ainda muito claro o conceito de direito integrado ambiental (o conceito aparece, sobretudo, na avaliação integrada de impacto ambiental), ele aponta para a necessidade de uma proteção global sistemática que não se reduza à defesa isolada dos componentes ambientais naturais (ar, luz, água, solo vivo e subsolo, flora, fauna) ou dos componentes humanos (paisagem, patrimônio natural e construído, poluição). As consequências de uma proteção integrada do ambiente são relevantes sob vários pontos de vista. $^{11}$

Assim com base na distribuição de competências analisada alhures, o modelo constitucional é um sistema de atuação coordenada e paralela, com a enumeração dos poderes da União (art. 21 e 22 da CF), poderes remanescentes aos Estados (art. 25 da CF) e local aos Municípios (art. 30 da CF). ${ }^{12}$ No que tange às competências materiais ou administrativas, relacionando-se o art. 225, VI da Constituição Federal, combinado com o art. 23 da Constituição Federal, àqueles que de alguma maneira aplicam políticas públicas, cabe a União

elaborar as políticas gerais, bem como agir nacionalmente. O Município tem competência exercida por meio da Lei Orgânica, leis complementares e leis ordinárias e outros atos normativos, e, como afirmado por Gilmar Ferreira Mendes, caso existam conflitos resolve-se a questão pelo sistema de preponderância de interesses, sendo que o mais amplo da União deve prevalecer aos mais restritos. ${ }^{13}$

\footnotetext{
11 CANOTILHO, José Joaquim gomes. Estado Constitucional Ecológico e Democracia Sustentada. In: FERREIRA, Heline Silvini; LEITE, José Rubens Morato. Estado de Direito Ambiental: tendências, aspectos constitucionais e diagnósticos. Rio de Janeiro: Forense, 2004, p.8

12 SILVA, José Afonso da. Direito Ambiental Constitucional. 7. São Paulo: Malheiros. 2009. p. 71

13 MENDES, Gilmar Ferreira; COELHO, Inocêncio Mártires; BRANCO, Paulo Gustavo Gonet. Curso de Direito Constitucional. 2. ed. São Paulo: Saraiva. 2008, p. 820.
} 
exercida por meio da Lei Orgânica, leis complementares e leis ordinárias e outros atos normativos, e, como afirmado por Gilmar Ferreira Mendes, caso existam conflitos resolve-se a questão pelo sistema de preponderância de interesses, sendo que o mais amplo da União deve prevalecer aos mais restritos. ${ }^{13}$

Paulo Affonso Leme Machado critica a competência comum mesmo antes da criação da Lei Complementar 140/11 referida anteriormente, pois entende que a atuação conjunta descoordenada pode ser mais prejudicial ao meio ambiente do que se fosse atribuída somente a um deles:

O perigo da simultaneidade de competências para a implementação do controle ambiental é que todos os entes federados ficaram competentes, mas nenhum deles tem assumido especificamente a melhoria da qualidade das águas, do ar e do solo e nenhuma instância governamental se responsabiliza pela conservação das florestas e da fauna. ${ }^{14}$

A complexidade maior reside na distribuição de competências legislativas ou formais, pois conforme analisado observa-se que a competência para legislar sobre o meio ambiente é concorrente da União, dos Estados e do Distrito Federal (art. 24 da CF), possuindo o Município somente competência para suplementar a legislação federal e a legislação estadual.

Inúmeras são as dificuldades encontradas para delimitar as competências legislativas, pois o meio ambiente segundo art. 225 da CF é um bem uso comum do povo e a qualidade ambiental afeta a todos indistintamente. Assim é difícil estabelecer limites para a esfera nacional, regional e local.

Diante da complexidade desse problema, a teoria constitucional do Estado constrói solução com base em um princípio capaz de racionalizar repartição das competências constitucionais. Trata-se do princípio da subsidiariedade.

Assim será analisado o princípio da subsidiariedade em matéria ambiental para entes Municipais, que, na interpretação de José Alfredo de Oliveira Baracho, ${ }^{15}$ é uma atuação subsidiária dos entes maiores, no momento em que a ação local não for possível e/ou eficiente.

\footnotetext{
14 MACHADO, Paulo Affonso Leme. Direito Ambiental Brasileiro. 22. ed. São Paulo: Malheiros. 2014, p. 124.

15 BARACHO, José Alfredo de Oliveira. O Princípio de Subsidiariedade: conceito e evolução. Rio de Janeiro: Forense, 1996, p. 92.
} 


\subsection{Princípio da subsidiariedade}

Podemos encontrar o princípio da subsidiariedade incorporado, mas não de forma expressa, no texto constitucional, em razão do modo como foi elaborada a repartição de competências, bem como o fortalecimento do Município, com inclusão como ente da Federação, demonstrada a intenção do constituinte originário por uma descentralização, o que está em conformidade com o princípio da subsidiariedade na repartição de competências constitucionais.

É um princípio novo no sistema brasileiro, embora ele já faça parte da evolução da Comunidade Econômica Europeia (Tratado de Maastrich), pois é o documento mais importante que adota o princípio da subsidiariedade. ${ }^{16}$

Maria Sylvia Zanella Di Pietro cita o art. $3^{\circ}-\mathrm{B}$ do Tratado da União Europeia como exemplo contemporâneo da aplicação do princípio da subsidiariedade, senão vejamos:

A comunidade age nos limites das competências que lhe são conferidas e dos fins que lhe são assinalados pelo presente. Nas matérias que não são de sua exclusiva competência, intervém, conforme o princípio da subsidiariedade, somente se e na medida em que os objetivos das ações previstas não podem ser suficientemente realizados pelos Estadosmembros. ${ }^{17}$

Outro exemplo oriundo do sistema comparado é o caso da Espanha, onde a legislação conformadora de princípios de proteção ambiental é feita pelo próprio Estado, deixando as medidas mais específicas para as leis das Comunidades Autônomas. Neste sistema não é permitido que as Comunidades Autônomas sejam mais brandas em relação à proteção já fixada pelo Estado, pois aí seria caso de violação do princípio da subsidiariedade. ${ }^{18}$

Já na Constituição Argentina de 1994 (art. 41, § 3º), a Nação Argentina ditará as normas contendo os pressupostos mínimos de proteção ambiental, permitindo-se às Províncias a complementação.

José Alfredo de Oliveira Baracho define subsidiariedade como um sistema em que

Os Estados membros confiam às instituições comuns, nos termos do princípio da subsidiariedade, as competências necessárias para manter as tarefas que podem realizar, de maneira mais satisfatória do que os estados isoladamente [...] A comunidade não atua apenas para executar as tarefas que lhe são confiadas pelos tratados, na realização

\footnotetext{
${ }^{16}$ ANTUNES, Paulo de Bessa. Federalismo e Competência Ambientais no Brasil. Rio de Janeiro: Lumen Juris, 2007, p. 186.

${ }^{17}$ DI PIETRO, Maria Sylvia Zanella. Parcerias na administração pública: concessão, permissão, terceirização, parceria público-privada e outras formas. 5. ed. 2. reimpressão. São Paulo: Atlas, 2006. p. 34.

${ }^{18}$ MACHADO, Paulo Affonso Leme. Direito Ambiental Brasileiro. 22. ed. São Paulo: Malheiros, 2014, p. 114.
} 
dos objetivos definidos por eles. Quando as competências não são exclusivamente, ou por complementaridade, devolvidas à Comunidade, ela em sua forma de atuação age na medida em que a realização de seus objetivos exige intervenção, porque suas dimensões ou seus efeitos ultrapassam as fronteiras dos estados-membros. Por essa razão, as tarefas podem ser empreendidas de maneira mais eficaz, pela própria comunidade, em lugar dos estados atuando separadamente. ${ }^{19}$

Com a promulgação da Constituição de 1988, a tendência municipalista reforça a utilização do princípio da subsidiariedade, principalmente relacionada à matéria ambiental, pois a Constituição estabeleceu competências materiais comuns e competências legislativas concorrentes, impondo também o dever de todo o Poder Público na defesa e proteção do meio ambiente.

Podemos assim fazer uma nova interpretação das competências legislativas em matéria ambiental, favorecendo o Município em relação à União e aos Estados, fundamentando-se o princípio da subsidiariedade, segundo o qual o ente federativo superior só deverá atuar se o ente inferior não tiver condições adequadas de exercê-lo de forma eficaz, privilegiando assim a atuação do Município, por ser melhor conhecedor de seu território, das necessidades, vontades e dos valores da sociedade local.

Mesmo não figurando expressamente no rol das competências legislativas concorrentes (art. 24), mas ante a competência de interesse local e poder de suplementar as legislações federal e estadual (art. 30, I e II) e por determinação do art. 225 que estabelece que é dever de todo o Poder Público a proteção ambiental, o Município está autorizado a dar um tratamento mais restritivo a certas questões ambientais que afetem negativamente os seus habitantes.

Tratando do princípio da subsidariedade, Paulo de Bessa Antunes explica que

O objetivo fundamental do princípio é a construção de parâmetros que sejam capazes de limitar a atuação do Estado e de lhe impor obstáculos sempre que, nos casos concretos, as soluções dos problemas sejam mais bem encaminhados pela própria sociedade a atuação de seus diferentes agentes. ${ }^{20}$

\footnotetext{
19 BARACHO, José Alfredo de Oliveira. O princípio da subsidiariedade: conceito e evolução. Rio de Janeiro: Forense, 1997, p. 72.

20 ANTUNES, Paulo de Bessa. Federalismo e Competência Ambientais no Brasil. Rio de Janeiro: Lumen Juris, 200 , p. 176.
} 
Nesse sentido, o princípio da subsidiariedade traduz a ideia de uma maior racionalidade na distribuição de competências, em especial naquelas que devam ser realizadas por todos os entes da federação e que possam gerar conflitos, como ocorre com a relativa ao meio ambiente. Jussara Aparecida Bratz argumenta que "Para solução de tais conflitos, surge o princípio da subsidiariedade, estabelecendo se injusto e ilícito adjudicar a uma sociedade maior o que é ainda capaz de fazer com a eficácia uma sociedade menor". ${ }^{21}$

Assim entende-se que os municípios com fundamento no princípio da subsidiariedade poderão inovar na proteção do interesse local e na realização do interesse público. Mais precisamente, com base no art. 225, pode-se concluir que a legislação municipal não precisa restringir-se a somente suplementar a legislação federal e estadual. Pode e deve inovar tanto em termos gerais, quanto em relação a regras específicas, desde que não viole o estabelecido pela própria Constituição e não fuja dos padrões mínimos estabelecidos na legislação nacional e estadual. A exceção a esse regramento se dá quando a própria lei nacional ou estadual permite a legislação ampla pelo Município, como podemos encontrar no art. $182 \mathrm{da} \mathrm{CF}$, que estabeleceu a política urbana.

Demonstrado que é possível e legítimo, no marco da própria distribuição de competências estabelecida na Constituição Federal de 1988, o Município legislar sobre matéria ambiental, verificar-se-á como são fundamentadas as decisões judiciais em matéria de repartição de competências municipais ambientais, tomando como exemplo o caso do uso das sacolas plásticas.

\subsection{A proibição do uso de sacolas plásticas}

Analisam-se agora argumentos utilizados em algumas ações diretas de inconstitucionalidade sobre a distribuição de competências legislativas na Constituição Federal quanto ao uso de sacolas plásticas.

Foram identificadas duas ações diretas de inconstitucionalidade ajuizadas no Supremo Tribunal Federal contra leis estaduais (Estado do Espírito Santo e Estado do Rio de Janeiro), uma ação direta de inconstitucionalidade ajuizada no Tribunal de Justiça do Estado do Rio Grande do Sul e várias ações diretas de inconstitucionalidade no Tribunal de Justiça do Estado de São Paulo.

\footnotetext{
${ }^{21}$ BRATZ, Jussara Aparecida. Competência do município para legislar em matéria ambiental à luz do princípio da subsidiariedade. Revista Interesse Público, Belo Horizonte, nº 67, ano XIII, maio/junho 2011, p. 272.
} 
No Espírito Santo, a Lei 8.745/2007 obriga os estabelecimentos comerciais do Estado a utilizarem, para acondicionamento de produtos, embalagens plásticas oxibiodegradáveis.

Foi impugnada por meio de Ação Direta de Inconstitucionalidade ${ }^{\circ} 4431$ no Supremo Tribunal Federal, proposta pela Associação Brasileira da Indústria de Material Plástico (ABIPLAST). Já existe parecer do Procurador Geral da República (PGR) opinando pela constitucionalidade da norma estadual com o seguinte fundamento:

Referida lei vem ao encontro das exigências constitucionais de proteção ao meio ambiente, de forma que haveria razoável consenso quanto ao fato de que as normas federais fixem patamares mínimos de proteção ambiental, o que não exclui a possibilidade de os demais entes federados estipularem condições mais rígidas que as normas federais. $^{22}$

Já a Ação Direta de Inconstitucionalidade nº 4483 (Supremo Tribunal Federal) contra a Lei Estadual 5.502/2009 do Rio de Janeiro questiona o regramento que obriga os estabelecimentos comerciais a recolher e substituir sacolas e sacos plásticos usados como embalagens dos produtos. A ação foi ajuizada pela Confederação Nacional do Comércio de Bens, Serviços e Turismo (CNC). O principal argumento é que a competência para legislar sobre a proteção do meio ambiente seria somente da União. O Procurador-Geral da República também já emitiu parecer pela constitucionalidade da lei utilizando o argumento utilizado pelo Min. Ricardo Lewandowski ao julgar pedido liminar de liminar na ADI 3.937-MC/SP, nos seguintes termos:

Como argumento final, tenho defendido não apenas em sede acadêmica, mas também em algumas decisões que proferi já na corte estadual a que pertenci, como também tive oportunidade de manifestar esse entendimento nesta Suprema Corte, no sentido de que em matéria de proteção ao meio ambiente e em matéria de defesa da saúde pública nada impede que a legislação estadual e a legislação municipal sejam mais restritivas do que a legislação da União e a legislação do próprio Estado, em se tratando de municípios. ${ }^{23}$ (grifos nosso)

\footnotetext{
22 BRASÍLIA. Supremo Tribunal Federal. ADI No 4431. Partes: Associação Brasileira da Indústria de Material Plástico (ABIPLAST) e Estado do Espírito Santo. Disponível em: http://www.stf.jus.br/portal/processo/verProcessoAndamento.asp?incidente=3909623. Acesso em: 27 de julho de 2015.

23 BRASÍLIA. Supremo Tribunal Federal. ADI no 4483. Partes: Confederação Nacional do Comércio de Bens, Serviços e Turismo (CNC) e Estado do Rio de Janeiro. Disponível em:http://redir.stf.jus.br/estfvisualizadorpub/jsp/consultarprocessoeletronico/ConsultarProcessoEletronico.jsf?seqobj etoincidente=3980287. Acesso em: 27 de julho de 2015.
} 
Outro argumento utilizado pelo Procurador-Geral da República é que se deve assegurar aos entes estaduais e municipais certa dose de criação e experimentação legislativa e administrativa, evitando-se que figurem como meros expectadores do processo decisório, promovendo-se o princípio do pacto federativo.

Em relação às leis municipais há vários casos já julgados em ações diretas de inconstitucionalidade no Estado de São Paulo. A Lei Municipal nº 6.481/09 de Guarulhos previa o uso de sacolas plásticas biodegradáveis, oxibiodegradáveis ou retornáveis nos estabelecimentos comerciais. Sua eficácia foi suspensa por decisão do Desembargador Maurício Vidigal na Ação Direta de Inconstitucionalidade $n^{\circ}$ 994.09.228314-7. ${ }^{24}$ Outros casos: Lei Municipal n 14.383/2012 de Campinas (Ação Direta de Inconstitucionalidade $\mathrm{n}^{\circ}$

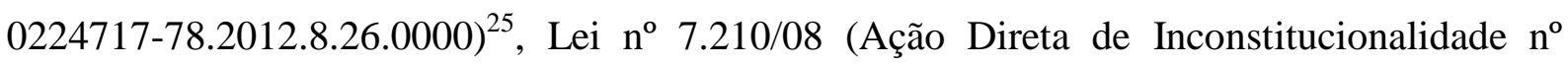
0230256-30.2009.8.26.000) ${ }^{26}$ e Lei de São José do Rio Preto (Ação Direta de Inconstitucionalidade $\left.\mathrm{n}^{\mathrm{o}} 0121455-49.2011 .8 .26 .000\right){ }^{27}$

Na Ação Direta de Inconstitucionalidade contra a Lei do Município de São José do Rio Preto, o relator Des. Walter de Almeida Guilherme argumentou que

A Constituição Federal outorgou aos Municípios a competência administrativa comum, mas a competência legislativa concorrente fora distribuída somente para os demais entes, com exclusão dos Municípios. Assim, somente poderia o Município legislar ambientalmente suplementando a lei federal estadual no que couber, o que não teria sido o caso.

O voto do Des. José Roberto Bedran segue o mesmo posicionamento, pois entendeu que o interesse da preservação do meio ambiente não poderia ser considerado predominante do âmbito local, tratando-se, na verdade, de assunto de concorrente interesse regional e nacional (CF, art. 24, VI). Argumentou que embora louváveis os bons propósitos da lei, a

\footnotetext{
24 SÃO PAULO. Tribunal de Justiça. ADI no 994.09.228314-7. Partes: Sindicato da Indústria de Material Plástico do Estado de São Paulo e Município de Guarulhos. Rel. Des. Maurício Vidigal. Julgado em 24 de novembro de 2011. Disponível em: https://esaj.tjsp.jus.br/cpo/sg/show.do?processo.foro=990\&processo.codigo=RMZ018O2B0000. Acesso em: 27 de julho de 2015.

25 SÃO PAULO. Tribunal de Justiça. ADI no 0224717-78.2012.8.26.0000, Rel. Des. Antônio Carlos Malheiros. Partes: Sindicato da Indústria de Material Plástico do Estado de São Paulo e Município de Campinas. Julgado em 27/03/2013. Disponível em: https://esaj.tjsp.jus.br/cpo/sg/show.do?processo.foro=990\&processo.codigo=RMZ018O2B0000. Acesso em: 27 de julho de 2015. ${ }^{26}$ SÃO PAULO. Tribunal de Justiça. ADI nº 0230256-30.2009.8.26.000. Rel. Des. José Roberto Bedran. Partes: Sindicato da Indústria de Material Plástico do Estado de São Paulo e Município e Município de Jundiaí. Julgado em: 03/02/2011. Disponível em: https://esaj.tjsp.jus.br/cpo/sg/show.do?processo.foro=990\&processo.codigo=RMZ018O2B0000. Acesso em: 27 de julho de 2015.

27 SÃO PAULO. Tribunal de Justiça. ADI nº 0121455-49.2011.8.26.000, Rel. Des. Walter de Almeida

Guilherme. Partes: Sindicato da Indústria de Material Plástico do Estado de São Paulo e Município de São José do Rio Preto. Julgado em 23/11/2011. Disponível em: https://esaj.tjsp.jus.br/cpo/sg/show.do?processo.foro=990\&processo.codigo=RMZ018O2B0000. Acesso em: 27 de julho de 2015 .
} 
degradação ambiental é objeto de preocupação nacional, sendo certo que a lei impugnada violava os princípios federativos e da repartição das competências.

Nos votos divergentes do Des. Renato Nalini e do Des. Roberto Mac Cracken, visualizase a tese oposta. O Des. Renato Nalini é categórico ao afirmar que o Município é ente da Federação e se este não possuir competência para legislar sobre questões ambientais de nada valeu a sua inclusão como ente federativo a partir da Constituição de 1988. O Des. Roberto Mac Cracken afirmou que o Poder Constituinte impôs combinação de esforços dos entes federativos para aumentar a tutela dos interesses arrolados, dentre eles o meio ambiente, não havendo, portanto, invasão da competência concorrente, até porque não há, no caso, edição de normas gerais sobre proteção ambiental, mas normas específicas sobre o descarte e a utilização de sacolas plásticas por entidades empresariais.

No Estado do Rio Grande do Sul, a Lei no 3.789/07 do Município de Uruguaiana foi objeto de Ação Direta de Inconstitucionalidade $\left(n^{\circ} 70063151179\right)^{28}$ ajuizada pelo Sindicato da Indústria de Material Plástico do Estado do Rio Grande do Sul (SINPLAST - RS). A lei determina a utilização de sacolas biodegradáveis e/ou "ecológicas" pelo comércio estabelecido naquela localidade, bem como a disponibilização aos consumidores (gratuita ou onerosa) de bolsas ou sacolas produzidas com materiais resistentes, e, portanto, reutilizáveis.

Dos vinte e cinco desembargadores que compõem o órgão especial, nove votos se filiaram à tese proposta pelo Des. Marcelo Bandeira Pereira e que segue o entendimento exarado no Tribunal de Justiça de São Paulo. Os demais dezesseis desembargadores seguiram o entendimento da relatora a Des. Iris Helena Medeiros Nogueira.

A Des. Iris Helena Medeiros Nogueira, relatora da ação, fundamentou a sua tese de constitucionalidade da lei municipal afirmando que

\footnotetext{
${ }^{28}$ RIO GRANDE DO SUL. Tribunal de Justiça. ADI no 70063151179. Rel. Des ${ }^{\mathrm{a}}$ Iris Helena Medeiros Nogueira. Partes: SINPLAST - RS (Sindicato da Indústria de Material Plástico do Estado do Rio Grande do Sul) e Município de Uruguaiana. Julgado em 15 de julho de 2015. Disponível em :

http://www.tjrs.jus.br/busca/search?q=fornecimento+de+sacolas+pl\%C3\%A1sticas\&proxystylesheet=tjrs index \&client=tjrs_index \&filter $=0 \&$ getfields $=* \& a b a=j u r i s \& e n t s p=a \quad$ politica-site $\& w c=200 \& w c \_m c=1 \& o e=U T F-$ 8\&ie=UTF-

$\underline{8 \& u d=1 \& l r}=$ lang pt\&sort=date $\% 3 \mathrm{AD} \% 3 \mathrm{AS} \% 3 \mathrm{Ad} 1 \&$ as $\_\mathrm{qj}=\&$ site=ementario\&as epq=\&as oq=\&as eq $=\& a s$ q=+\#main_res_juris. Acesso em: 27 de julho de 2015.
} 
[...] muito embora não se olvide ser de competência da União e dos Estados a edição de normas gerais de proteção do meio ambiente natural, nos termos do artigo 24, VI e $\S 1^{\circ}$, da Constituição Federal, deve ser observado que a própria $\mathrm{CF}$, em seu artigo 23 , VI, dispõe competir aos três níveis governamentais (União, Estados e Municípios) a proteção do meio ambiente e o combate à poluição com o que há a possibilidade de os municípios suplementarem os regramentos acerca da matéria. $\mathrm{O}$ artigo 30 também da Carta Constitucional delega aos entes municipais a autonomia para legislar sobre os assuntos de interesse local, suplementando normas superiores, sem contrariá-las.

A relatora cita, em reforço a sua interpretação, decisão do Tribunal de Justiça do Estado do Rio Grande do Sul em relação a uma lei do Município de Santa Cruz que estabelecia limites de ruídos. Nesse caso, o Tribunal de Justiça já esboçara o seu entendimento em relação à possibilidade de os Municípios legislarem de forma subsidiária em questões ambientais. $^{29}$

O Des. Luiz Felipe Silveira Difini afirmou que a jurisprudência do Supremo Tribunal Federal admite inclusive que o Município regule o horário de funcionamento do comércio. Razão maior tem para legislar sobre meio ambiente, amparado na Constituição, que lhe atribui competência para suplementar legislação federal ou estadual no que couber.

O voto divergente, acompanhado por nove desembargadores, foi enunciado pelo Des. Marcelo Bandeira Pereira. Ele fundamentou a divergência sustentando que a competência legislativa do Município para tratar do meio ambiente é suplementar e não concorrente, e isso está posto com toda a clareza no art. 24, inc. VIII, que prevê: "Compete à União, aos Estados e ao Distrito Federal legislar concorrentemente sobre: responsabilidade por dano ao meio ambiente, ao consumidor, a bens e direitos de valor artístico [...]". Afirmando não ser por acaso que o Poder Constituinte Originário não incluiu o Município nesta competência. Não sendo, portanto, ao Município permitido estabelecer proibição e regramento que não conste no ordenamento federal ou estadual. E por fim afirma que cada Município por maior que seja sua autonomia não pode criar regras gerais, em face da unidade da federação. Afirma ainda

\footnotetext{
29 “AÇÃO DIRETA DE INCONSTITUCIONALIDADE. MUNICÍPIO DE SANTA CRUZ DO SUL. LEI Nº 2.608/94. ARTS. $8^{\circ}, 10,11$ DA Lei $n^{\circ}$ 01/L/79/79. COMPETÊCIA DO ENTE MUNICIPAL PARA DISPOR SOBRE MEIO AMBIENTE E ECOLOGIA. 1. O legislador constitucional visou à preservação do interesse local, ao atribuir aos Municípios competência para legislar sobre assuntos de interesse local e suplementar a legislação federal e estadual, no que couber (art. 30), e ao dispor que no âmbito da legislação concorrente, a competência da União limitar-se-á a estabelecer normas gerais (art. $24, \S 1^{\circ}$ ). Ademais, a proteção do meio ambiente e o combate à poluição, em qualquer de suas formas, é matéria de competência comum da União, dos Estados, do Distrito Federal e dos Municípios, segundo o art. 23 da Carta Republicana. E, por simetria, a Constituição Estadual, em seu art. $8^{\circ}$, assegura aos Municípios autonomia política, administrativa e financeira, advindo daí a competência do ente municipal para dispor sobre meio ambiente e ecologia. 2. Inexistindo lei formal, no âmbito federal, a dispor sobre normas gerais em matéria de poluição sonora, tanto não podendo ser atribuído à Resolução $\mathrm{n}^{\circ}$ 01/90 do Conselho Nacional do Meio Ambiente - CONAMA - não se reconhece inconstitucionalidade em lei municipal de que estabelecera limites máximos de ruído diversos daqueles prescritos na referida Resolução ${ }^{\circ} 001$ do CONAMA. Precedente do STF. AÇÃO DIRETA DE INCONSTITUCIONALIDADE JULGADA IMPROCEDENTE, POR MAIORIA. (Ação Direta de Inconstitucionalidade N 70054990197 , Tribunal Pleno, Tribunal de Justiça do RS, Relator: Eduardo Uhlein, Julgado em 25/11/2013).”
} 
que é impossível admitir que numa determinada cidade se obrigue a utilização de sacolas plásticas e noutras não, sem que haja razão alguma peculiar a justificar essa distinção.

\section{CONSIDERAÇÕES FINAIS}

Este artigo teve por objeto a competência dos Munícipios para editarem leis a respeito do meio ambiente. Analisou-se o modelo de repartição de competências adotados pela Constituição de 1988 para fundamentar a possibilidade de os Municípios editarem leis sobre o meio ambiente. Constatou-se que o Poder Constituinte Originário resguardou o interesse local, ao atribuir aos Municípios competência para legislar sobre assuntos de interesse local e para suplementar a legislação federal e estadual, no que couber (art. 30, I e II), e ao dispor que no âmbito da legislação concorrente a competência da União limitar-se-á a estabelecer normas gerais (art. $24, \S 1^{\circ}$ ). Ademais, a proteção do meio ambiente e o combate à poluição, em quaisquer de suas formas, é matéria de competência administrativa comum da União, dos Estados, do Distrito Federal e dos Municípios, segundo o art. 23.

Tomando como exemplo leis municipais em relação às sacolas plásticas, que foram objeto de ações diretas de inconstitucionalidade, constatou-se que tanto os Desembargadores dos Tribunais de Justiça do Estado do Rio Grande do Sul e do Tribunal de Justiça do Estado de São Paulo, bem como os Ministros do Supremo Tribunal Federal, fazem a análise da arguição de (in)constitucionalidade formal das leis ambientais editadas pelos Municípios sempre de modo conjunto com a (in)constitucionalidade material.

Assim o entendimento e aplicação do princípio da subsidiariedade é fundamental para corroborar a tese de que os Municípios têm competência para editar leis que restrinjam ou criem proibições em prol do meio ambiente, pois estas se mostram em harmonia com os ditames da Constituição Federal.

\section{REFERÊNCIAS}

ANTUNES, Paulo de Bessa. Federalismo e Competência Ambientais no Brasil. Rio de Janeiro: Lumen Juris, 2007.

BARACHO, José Alfredo de Oliveira. O Princípio de Subsidiariedade: conceito e evolução. Rio de Janeiro: Forense, 1996.

BRATZ, Jussara Aparecida. Competência do município para legislar em matéria ambiental à luz do princípio da subsidiariedade. Revista Interesse Público, Belo Horizonte, $\mathrm{n}^{\circ}$ 67, ano XIII, maio/junho 2011. 
BRASÍLIA. Supremo Tribunal Federal. Adi No 4431. Partes: Associação Brasileira da Indústria de Material Plástico (ABIPLAST) e Estado do Espírito Santo. Disponível em: http://www.stf.jus.br/portal/processo/verProcessoAndamento.asp?incidente=3909623 Acesso em: 27 de julho de 2015

CANOTILHO, José Joaquim Gomes. Estado Constitucional Ecológico e Democracia Sustentada. In: FERREIRA, Heline Silvini; LEITE, José Rubens Morato. Estado de Direito Ambiental: tendências, aspectos constitucionais e diagnósticos. Rio de Janeiro: Forense, 2004.

DI PIETRO, Maria Sylvia Zanella. Parcerias na administração pública: concessão, permissão, terceirização, parceria público-privada e outras formas. 5. ed. 2. reimpressão. São Paulo: Atlas, 2006.

MACHADO, Paulo Affonso Leme. Direito Ambiental Brasileiro. 22. ed. São Paulo:

Malheiros, 2014.

MENDES, Gilmar Ferreira; COELHO, Inocêncio Mártires; BRANCO, Paulo Gustavo Gonet. Curso de Direito Constitucional. 2. ed. São Paulo: Saraiva, 2008.

RIO GRANDE DO SUL. Tribunal de Justiça. ADI n ${ }^{\circ}$ 70063151179. Rel. Des ${ }^{a}$ Iris Helena Medeiros Nogueira. Partes: SINPLAST - RS (Sindicato da Indústria de Material Plástico do Estado do Rio Grande do Sul) e Município de Uruguaiana. Julgado em 15 de julho de 2015. Disponível em :

http://www.tjrs.jus.br/busca/search?q=fornecimento+de+sacolas+pl\%C3\%A1sticas\&prox ysty $\underline{\text { lesheet }=\text { tjrs_index \&client }=\text { tjrs_index } \& \text { filter }=0 \& \text { getfields }=* \& a b a=j u r i s \& e n t s p=a \quad \text { politica- }}$ site $\& w c=200 \& w c \_m c=1 \& o e=U T F-8 \& i e=U T F-$

$\underline{8 \& u d=1 \& l r=l a n g \_p t \& s o r t=d a t e \% 3 \mathrm{AD} \% 3 \mathrm{AS} \% 3 \mathrm{Ad} 1 \& \text { as_qj=\&site=ementario\&as_epq=\&as }}$ oq=\&as_eq=\&as_q=+\#main_res_juris. Acesso em: 27 de julho de 2015.

SILVA, José Afonso da. Direito Ambiental Constitucional. 7. ed. São Paulo: Malheiros. 2009.

SÃO PAULO. Tribunal de Justiça. ADI n ${ }^{\circ}$ 994.09.228314-7. Partes: Sindicato da Indústria de Material Plástico do Estado de São Paulo e Município de Guarulhos. Rel. Des. Maurício Vidigal. Julgado em 24 de novembro de 2011. Disponível em: 
https://esaj.tjsp.jus.br/cpo/sg/show.do?processo.foro=990\&processo.codigo=RMZ018O2B00 00. Acesso em: 27 de julho de 2015

SÃO PAULO. Tribunal de Justiça. ADI nº 0224717-78.2012.8.26.0000, Rel. Des. Antônio

Carlos Malheiros. Partes: Sindicato da Indústria de Material Plástico do Estado de São Paulo

e Município de Campinas. Julgado em 27/03/2013. Disponível em:

https://esaj.tjsp.jus.br/cpo/sg/show.do?processo.foro=990\&processo.codigo=RMZ018O2B00 00. Acesso em: 27 de julho de 2015.

SÃO PAULO. Tribunal de Justiça. ADI nº 0230256-30.2009.8.26.000. Rel. Des. José Roberto Bedran. Partes: Sindicato da Indústria de Material Plástico do Estado de São Paulo e Município e Município de Jundiaí. Julgado em: 03/02/2011. Disponível em:

https://esaj.tjsp.jus.br/cpo/sg/show.do?processo.foro=990\&processo.codigo=RMZ018O2B00 00. Acesso em: 27 de julho de 2015.

SÃO PAULO. Tribunal de Justiça. ADI no 0121455-49.2011.8.26.000, Rel. Des. Walter de Almeida Guilherme. Partes: Sindicato da Indústria de Material Plástico do Estado de São Paulo e Município de São José do Rio Preto. Julgado em 23/11/2011. Disponível em: https://esaj.tjsp.jus.br/cpo/sg/show.do?processo.foro=990\&processo.codigo=RMZ018O2B00 00. Acesso em: 27 de julho de 2015. 